\title{
First person shot. New Forms of Subjectivity between Cinema and Intermedia Networks
}

\author{
Prof. Ruggerto Eugeni \\ Full Professor of Media Semiotics \\ Catholic University of the Sacred Heart \\ Largo Gemelli, 1 \\ 20127 Milan \\ ruggero.eugeni@unicatt.it
}

\begin{abstract}
The article analyzes the first person shot, a stylistic figure resulting from a radical transformation of the classical point of view or subjective shot within the contemporary media landscape. The first part of the article focuses on two main features of the first person shot. On the one hand, it is an intermedia figure, arising from the reciprocal interactions of technological innovations which unfolded on different media platforms: the steadycam and its derivatives, digital cameras and their miniaturized versions, surveillance equipments, videogames playable from a first-person perspective. On the other hand, it is an experiential figure, as it directly expresses the dynamic grasp of the world, enacted by a hybrid agent (a body - sensor), and consequently its perceptual, practical, emotional, living and ongoing experience.
\end{abstract}

The second part of the article considers the first person shot as a figure expressing in sensorial terms a well defined idea of subject and subjectivity. This idea contrasts with the main conceptions adopted by film and media scholars: the article analyzes the debate between J. L. Baudry and V. Sobchack and argues that both scholars - despite their different philosophical premisesconsider the subject as an entity defined by its position in a specific location. Rather, in the case of the first person shot the subject is continuously redefined through a constant shifting; hence the subject should be conceived as dis-posed and dis-located. Finally, the article argues that this conception of subject and subjectivity links film and media studies to current mind theories inspired by cognitive phenomenology, which elaborated a conception of subject as a dynamic agent involved in an ongoing narrative negotiation of selfhood through continuous flows of transformations.

Keywords: Body, experience, film studies, intermediality, media studies subject 


\section{Introduction}

In this article I will analyze a linguistic and stylistic figure which I consider characteristic of contemporary audiovisual media; I will call it «first person shot $\rangle^{1}$. First person shot represents the transformation of the classical figure of point of view shot-or subjective shot-, within the contemporary intermedia network.

The epistemological premise of my argument is that the figures of style are at the crossroad between two kinds of phenomena. On the one hand, they refer to some technologies which made possible their origin; on the other hand, the figures of style express abstract theoretical concepts in sensorial forms; in other words, they are figures of thought. This epistemological premise is needed to understand my analysis of first person shot. In the first part of my article I will analyze the different technologies that contributed to the transformation of point of view shot into first person shot; besides this, I will compare the two figures in order to highlight the first person shot specific features. In the second part of the article I will consider the first person shot as a figure of thought; I will argue that it urges film and media theory to rethink its idea of subject and subjectivity (i.e. subjective identity formation and expression), in order to shift from a "locative", "positional" and static conception of the subject to a dynamic, "dis-positional" and "dis-locative" one.

\section{From the point of view shot to the first person shot}

\subsection{Converging technologies: a genealogy of first person shot}

First person shot derives from five major technological and stylistic innovations which affected the film and media field from the beginning of the Eighties until now. It's worth noting that these innovations are not important in themselves, but rather for their dynamical interaction (see below).

The first innovation is the introduction of the Steadicam, marketed in 1975 but used extensively since the beginning of the Eighties. From this period and up to now, many film directors have used the Steadicam in order to reinvent the classical tracking shot ${ }^{2}$. Moreover, the new television series of the

1. I presented a first version of this article during the Conference "The Impact of Technological Innovations on the Historiography and Theory of Cinema" (Montreal, November 1-6, 2011). In this occasion I had the opportunity to discuss the paper with many colleagues: I thank them all, and especially Francesco Casetti, Antonio Somaini, Adriano D’Aloia, Frank Kessler and Vinzenz Hediger.

2. The first film which used the Steadicam was Bound for Glory (Al Ashby, U.S., 1976). Among the most important film which used this expressive instrument, The Shining (S. Kubrick, USA -GB 1980), Strange Days (Kathryn Bigelow, USA, 1995), La mort en direct (Deathwatch, Bertrand Tavernier, Fr- West Ger, UK, 1980), Snake Eyes (Brian De Palma, USA, 1998), The Russian Ark (Aleksàndr Sokurov, Russia - Germany, 2002) Elephant (Gus Van Sant, USA, 2003). 
Nineties have made extensive use of the Steadicam, which proved to be the ideal means to smoothly pass through confined spaces such as police stations rooms, hospital corridors, etc. The Steadicam implies a «subjective» camera's gaze: in other words, it expresses a perceptive and active grasp of reality, and therefore it manifests a living, lived, ongoing process of experience, made by an embodied and enworlded subject ${ }^{3}$.

A second innovation is the introduction of portable digital cameras at the beginning of the Nineties. On the one hand digital cameras reached an image quality close to that of movie equipments; on the other hand the lightness of the devices allowed operators to recover hand-held camera practices, typical of militant cinema, combat film or anthropological movies. These processes were intensively exploited in information shootings and video documentaries; at the same time, they became assets of docudrama or mockumentary productions, before finally reaching independent and mainstream feature films. In this way, the same forms of expression (shaky camera, «dirty» quality of the images, over and underexposure, etc.) can be found in very different products: documentaries and protest film, television series ${ }^{4}$, action and war movies ${ }^{5}$, reality TV shows, viral web videos, horror movies pretending to be the assembly of found footage materials, which survived the operator's death ${ }^{6}$, etc.

A third series of technological innovations is related to a new generation of miniaturized digital cameras, which allowed the introduction of helmet cameras (invented in 1987 by Mark Schulze, a San Diego director of photography, for the shooting of motorcycle racings), lipstick cameras, combat cameras, video cameras integrated into cellular telephones. The videos produced by this type of micro-cameras are today widespread, especially throughout the web: think for example of videos produced during military combat with helmet cam; their homemade parodies or remakes; automobile or motorcycle accidents taken from the point of view of the victims; videos witnessing «live» historical events (earthquakes in Japan or Turkey, revolts in

3. In the Steadicam system, "the camera system is attached to the support arm [of the operator] by means of a free-floating gimbal. In this manner, the camera operator is able to pan or tilt the camera at will, and move it up or down, or side to side, in a free-floating manner [...]. In short, the principal characteristic of the Steadicam system is that it stabilizes the camera by using balance, isolation and inertia [...] The most important characteristic of the Steadicam is the quality of movement it gives: movement which is not perceived through its defects, but rather through its perfection. On the contrary, the handheld camera is often used to emphasize instability, dynamism, struggles [...]" (Ferrara, 2001: 19-20 and 73)

4. Like for instance Homicide, created by Paul Attanasio, from 1993 to 1999; Riget by Lars von Trier from 1994 to 1995, The Shield, created by Shawn Ryan in 2002, and so on.

5. See by way of example Saving Private Ryan (Steven Spielberg, U.S.A., 1998), Black. Hawk Down (Ridley Scott, USA, 2001), The Hurt Locker (Kathryn Bigelow, USA, 2008), etc.

6. We can remind The Blair Witch Proiect (Daniel Myrick and Eduardo Sanchez, USA, 1999), Rec (Jaime Balaguer and Paco Plaza, Sp. 2007) and Rec II (2009), Diary of the Dead (George A. Romero, 2007), Paranormal Activity (Oren Peli, USA, 2007) and Paranormal Activity II (Id, USA, 2010), Cloverfield (Matt Reeves, 2008), etc.. 
the North Africa countries, the death of Qaddafi, just to quote some recent cases), etc..

A specific area related to the development of digital video was the video surveillance and control, which we consider the fourth technological innovation behind the development of the first person shot. Since the late Nineties, digital technology pushed up the market of CCTV (Close Circuit Televisions), thanks to three factors: most sensitive sensors, the possibility of controlling multiple cameras simultaneously, and a significant reduction of prices?. This cameras (the so-called «pinhole video cameras», miniature still cameras, spy cameras, etc.) are easy to connect to digital communication networks, thus enabling the video surveillance of public and private spaces even from a distance. As a result, video monitored areas spread rapidly; moreover, the experience of watching video showing ordinary life spaces and actions became more and more diffused.

The fifth technological and linguistic innovation is the development of videogames playable in first person with sufficient speed, fluidity and realism ${ }^{8}$. Within the video game domain, the term "first person shot" refers to the possibility for the player to perform the actions planned by the game, keeping the visual and aural position of a specific character, whose body isn't usually entirely visible and which is commonly called «avatar». Three videogames genres normally use this figure: the shooters, the vehicle (flight, drive tanks, racing) simulators, and some graphic adventure games. The roots of these genres are established in the Seventies with games such as Maze War (1973) and Spasim (1974); however, the first person shot videogames spread in the Nineties with the great success of shooters such as Wolfenstein 3D (1992) and its direct successor Doom; the incredible success of the latter opened the doors to products such as Duke Nukem 3D (1996), Quake (1996), Half Life (1998). At the same time, the first-person point of view was adopted for many point-andclick graphic adventure games, in particular for the popular series opened by Myst (Cyan - Broderbund Software, 1993; it was followed during the following years by Riven and Myst III: Exile). Since the late Nineties up today, first person videogames have been evolving in two directions: on the one hand they have become more realistic, on the other hand videogame narrative designers contaminated shooters, adventure game and drive simulators. As a result, we

7. 'Digital cameras have many advantages for surveillance work, including small size, 'instant' pictures, and good sensitivity in low light conditions. No space is needed for film cassettes and the flash cards used to store images are tiny. They are easy to load; flipping in a memory card is easier than loading film. The pictures are almost instantly available, since there is no need to take film to a lab for processing. Thus, the pictures can be viewed and retaken if they didn't work the first time, and they can be viewed in private without going through a public film lab. They are also easy to upload to a computer network, since no scanning or conversion is usually necessary" (Petersen, 2001: 461)

8. See, in particular, Rehac, 2008 and Helrander, 2009. About the relationships between videogames and new media see the seminal Wardrip-Fruin and Harrigan (eds.), 2004. 
find today a new generation of war games such as the series of Medal of Honor (Dreamworks - Electronic Arts since 1999), Call of Duty (Activision / Infinity Ward, from 2003), Crisis (from 2007); and a new kind of driver and racing simulators such as the Grand Theft Auto series (Zachary Jones \& Dave Clarke, from 1997).

As previously stated, my exposition has been forced to isolate the five different sectors of technological innovations; however, it is very important to highlight the fact that the first person shot emerges from the complex interaction of the different flows of transformations. On the one hand, each technological innovation unfolded within a specific media platform: mainstream or independent cinema for steadicam; television programs for portable digital cameras; web sites and social networks for videos produced with miniaturized digital cameras; private devices for video surveillance; personal computers and game consoles for first person shooters. On the other hand, however, the different media platform remediated each other in a complex way: in this sense the first person shot is a radically intermedial figure. I make just a few examples in this regard. First, the use of the Steadicam in movies such as Strange Days or Elephant is (differently) inspired by first person shot videogames; similarly, many online videos shot with helmet cam are the parody of contemporary videogames. Conversely, various videogames reproduce hand-held camera effects, e.g. when the "camera" follows the character along a war action or a football match. Thirdly, CCTV and video surveillance devices were re-used in many artistic video installations ${ }^{9}$, in television information and docu-fiction, in tv crime series ${ }^{10}$, and became a critical feature of tv reality shows; moreover, surveillance cameras were used as a dramaturgic device in many film, like for instance Raising Cain (Brian de Palma, USA, 1992), Enemy of the State (Tony Scott, USA 1992), Caché (Michael Haneke, France - Austria - Germany - Italy, 2005), and so on. Finally, we can find movies which remediate, reincorporate and recombine almost all the different technological tools mentioned above: a clear example is Redacted (Brian De Palma, USA, 2007).

\subsection{A comparison between firstperson shot and point of view shot}

After identifying the five major technological innovations responsible for the advent of first person shot, I'll try to determine the characteristic features of this figure. For this purpose, it is worth comparing the first person shot with the classical point of view shot or «subjective shot» ${ }^{11}$ In this regard, I will highlight three main differences.

9. Levin, Frohne, Weibel, 2002; Somaini, 2010.

10. Aaron Doyle, 2003.

11. On the birth, evolution and semiotic features of the filmic point of view shot see Branigan, 1984 and Casetti, 1991. More generally, on the cinematographic expression of subjectivity, see Chateau (ed.), 2011. 
First, the point of view shot is a typical figure of the film and audiovisual media; on the contrary, the first person shot is an intermedia figure. The point of view shot is typically used in movies and television programs, and it is scarcely borrowed by other media. On the contrary, as we have just seen, the first person shot is a figure generated by the cross influence of different media platforms.

A second difference between the first person shot and the point of view shot is that the latter requires a grammatical construction implying a first shot showing the character(s) who is (or are) watching, and a second one of the object of their vision; besides, this syntactical feature makes it difficult to keep the subjective point of view for a long period ${ }^{12}$. In contrast, the first person shot breaks these rules: the avatar's face in first-person videogames never appears; in the combat videos taken by helmet cams, the soldier fighting can be seen only by accident; entire movies can be shot with a digital camera by hand (for example the horror movies quoted above), etc. To sum up, the first person shot entails a general extension of the principle of subjectivity implied (but partially manifested) by the point of view shot.

Finally, the point of view shot system is based on the implicit but fundamental distinction between the subject(s) who is (or are) watching inside the diegetic world, and the object of the camera which temporarily occupies their perceptual position. On the contrary, first person shot obliterates this distinction. There is certainly a polarity between first person shots attributable to the diegetic world's subjects (and thus similar to the classic point of view shot) and first person shot referable only to machines (for example the parts of a film taken from surveillance videos). Nonetheless, the salient feature of the first person shot is its hybrid nature of a sight belonging to a subject / object. In many cases, the definition of the ontological nature of the first person shot viewer is delayed or remains ambiguous. In other cases there is a metonymic relationship between the camera and the body's operator. Finally, in the case of video games neither a camera nor a viewer is present, since both the world framed and the act of framing are generated by the game software. In short, first person shot represents the sight of located, embodied, enworlded, active, dynamic, and hybrid agents: I will call them bodies - sensors.

To sum up, the first person shot is an intermedia figure directly exhibiting the dynamic grasp of the world enacted by a hybrid agent (a body - sensor), and consequently its perceptual, practical, emotional, living and ongoing experience.

12. With a few notable exceptions: The Lady in the Lake (Robert Montgomery, USA 1947) and the first part of The Dark Passage (Delmer Daves, USA, 1947). Both movies have been analyzed by Vivian Sobchack: see Sobchack, 2011 and 1992. 


\section{For a new theory of subject and subjectivity in film and media studies}

\subsection{The subject as position and location in Jean-Louis Baudry's and Vivian Sobchack's theories}

In this section I will consider the theoretical implication of the first person shot. As previously stated, I consider the first person shot as a figure which expresses in sensorial terms a key theoretical concept: the idea of subject and subjective identity. Since the question of the status of the subject is not new in the field of film studies, I will analyze firstly the debate on this matter. In particular, I will focus on the "Apparatus theories" of the Seventies and on their more recent revision by film scholars inspired by phenomenological theories.

The topic of the «subject» emerges within the debate about the ideological implications of the cinematic apparatus which takes place in France at the beginning of the Seventies ${ }^{13}$. In his influential intervention «Ideological Effects of the Basic Cinematographic Apparatus» (1970) ${ }^{14}$, Jean-Louis Baudry outlines a theory of the subject on the basis of the spectator's relationship with the "cinematic apparatus"; the latter is intended as the combination of technological devices that allow the appearance of the film image - it is the "appareil de base" of film -; in any case, particular attention is devoted to the more restricted system involving theater, projector and screen - it is the "dispositif " - which is the topic of a subsequent article.

Baudry's intervention can be summarized in two key points. First, the cinematic apparatus defines the subject as "position» and a "location" on the basis of filmic images. On the one hand, the single still frame defines the viewer's spatial location on the basis of the central and absolute point of view derived from Renaissance perspective ${ }^{15}$. On the other hand, different images define a «transcendental subject» who subsumes the fragmented and diversified flow of images into a coherent unity of consciousness.

Second, the apparatus produces an identification of the viewer with the transcendental subject, by means of a repetition of the Lacanian "mirror stage" -where the screen takes on the function of the Lacanian mirror ${ }^{16}-:$ «[... just as the mirror assembles the fragmented body in a sort of imaginary inte-

13. See Casetti, 1999: 184-203.

14. Baudry, 1986.

15. "The centre of this space coincides with the eye which Jean Pellerin Viator will so appropriately call the 'subject' [...] Based on the principle of a fixed point of reference, to which the visualized objects are defined, it specifies in return the position of the 'subject', the very spot it must necessarily occupy" (Baudry, 1986: 289).

16. «It is not specifically 'imaginary', nor as a reproduction of its first configuration, that the self finds a 'place' in the cinema. This occurs, rather, as a sort of proof or verification of that function, a solidification through repetition» (Baudry, 1986: 295) 
gration of the self, the transcendental self unites the discontinuous fragments of phenomena, of lived experience, into unifying meaning $\gg{ }^{17}$.

Moreover, the use of Lacan's mirror stage confirms and reinforces the idea of the subject as a «location» defined by visual data. Regarding this point, cinema manifests its ideological nature, since it «constitutes the 'subject' by the illusory delimitation of a central location [...] It is an apparatus destined to obtain precise idelogical effects, necessary to the dominant ideology: creating a phantasmatization of the subject, it collaborates with a marked efficacy in the maintenance of idealism ${ }^{18}$.

The idea of subject proposed by Baudry has been critically discussed, among others, by film scholars inspired by phenomenological theories. I shall focus in particular on arguments expressed by Sobchack, 1992. Sobchack's basic idea is that not only the spectator but also the film itself should be considered as a subject; indeed, the film expresses a perceptual, introceptive experience of an "enworlded" body as well as the spectator. As a consequence, «the direct engagement, $[\ldots]$ between spectator and film in the film experience cannot be considered a monologic one between a viewing subject and a viewed object. Rather, it is a dialogical and dialectical engagement of two viewing subjects who also exist as visible objects (if of different material and in different ways to be elaborated further)». More exactly, «[...] if we attempt to thematize and interpret the imbricated and dialectical correlations that exist between the correlational structure of the film's intentional movement and visual activity and the correlational structure of the spectator's intentional movement and visual activity, eight correlational possibilities emerge as primary ${ }^{19}$; on the basis of Sobchack's conception, the eight possibilities differ depending on two kind of factors: first, what is the object of the perceptive intentionality manifested by the film and the spectator (it can be directed either toward a noematic object, or towards the act of intentioning, or to the subject who performs the act of intentioning); second, whether the positions of the two subjects are or are not aligned.

Sobchack's arguments against Baudry's position are based upon this set of assumptions. According to Sobchack, Baudry (followed on this point by Christian $\mathrm{Metz}^{20}$ ) does not recognize that film constitutes a kind of subject; consequently, he depicts the cinematic experience as an embodiment acted by the apparatus into the passive spectator, and therefore as a kind of manipulative constitution of subjectivity - a theory dismissed as «paranoid» -. In other words, Sobchack applies to Baudry and Metz the same argument which she used against Lacan: the constitution of the subject shouldn't be taught as a «from the outside in» process, but rather as a «from the inside out» one ${ }^{21}$.

17. Ibid.

18. Ibid.

19. Sobchack, 1992: 278

20. Metz, 1982.

21. Sobchack, 1992: 99. 
Other film scholars inspired by phenomenological theories agree with Sobchack about this latter argument, although they use different approaches ${ }^{22}$.

If you compare Baudry's theory of subject with Sobchack's arguments, you can easily notice that Sobchack's criticism focuses just on the second point of Baudry's argument: phenomenologist film scholars attack the idea that the subject is defined by the apparatus through the construction of a defined visual location and its imposition to the spectator. In contrast, Sobchack's discussion leaves intact the first point of Baudry's theory, that is the idea that the subject is defined by the position within a distinct location. Within the different "correlational possibilities" designed by the scholar, the spectators are once again defined on the basis of a given location - which in this case corresponds to the position they assume in their relation with the scene they are viewing, with the act of viewing itself, or with themselves as being

\subsection{First person shot, or The subject as dis/position and dis/location}

I can now express the main argument of this second section of my article. The first person shot as an intermedia figure, leads to a radical recasting of the ideas of subject and subjectivity diffused in film studies. More exactly, we should contrast not only the view that the subject is defined "from the outside in" (Baudry's second point), but also the conception of the subject as defined by the position on a particular location (Baudry's first point). As a consequence, I do propose a conception of film subject as dis/located and dis/posed.

Let me first consider Baudry's second point. As previously stated, this point has already been criticized by Sobchack, whose description is perfectly suited to the first person shot. Indeed, the body - sensor constitute itself as a subject through the living experience of a sensory, active, emotional, cognitive grasp of the world, and trough a contemporary, ongoing, direct expression of such an experience. As a consequence, film spectators are not confronted with a transcendental and disembodied gaze to identify with; on the contrary, they are confronted with an embodied, situated, «enworlded» (although noncompletely-human) subject, and they have to define a kind of dialogical and dialectical engagement with it.

However, Sobchak's arguments misses criticizing Baudry's first point; therefore, she fails to consider the dynamical nature of the subject, which is on the contrary well expressed by the first person shot. Indeed, the first person shot shows a constant move of the body-sensor, often performing active and mobile explorations of the world. Furthermore, the first person shot is often fragmented and thus it requires editing procedures; accordingly, spectators are required to monitor and link the continuous shifts of the shots in order to

22. See in particular Casebier, 1991: 73-78, Shaw, 2008: 74-79. For a critique of Baudry's ideas from other positions see Aaron, 2007: 9-15. 
reorganize their experience in a coherent way. Hence, the idea of the subject as a posited and located entity, gives way to an idea of a dis/posited and dis/ placed subject. Subjects are neither "entities" nor "places"; indeed, they have an essentially temporal nature, since they are repeated and self - producing events.

\section{Conclusion: subject and subjectivity between media studies and neu- ro-cognitive findings}

In this article I focused on the first person shot, a stylistic figure widespread within the contemporary media landscape, which results from a radical transformation of the classical point of view or subjective shot. In the first part of my article I highlighted two key features of the first person shot. On the one hand, it is an intermedia figure, as it arises from the reciprocal interactions of different media platforms. On the other hand, it is an experiential figure, as it directly expresses the dynamic grasp of the world, enacted by a hybrid agent (a body - sensor), and consequently its perceptual, practical, emotional, living and ongoing experience.

In the second part of my article, I analyzed the first person shot as a figure expressing in sensorial terms a well defined idea of subject and subjectivity. This particular idea of subject contrasts with the main conceptions adopted by film and media scholars, who consider the subject as an entity defined by the position in a specific location. Rather, in the case of the first person shot the subject is continuously redefined through a constant shifting; hence the subject should be conceived as dis-posed and dis-located.

In conclusion, it is important to highlight the fact that such an idea of subject and subjectivity is not limited to film and media studies; rather, it is widely assumed in current neuroscience and cognitive science of mind influenced by phenomenology $\mathrm{y}^{23}$. In this field of studies the subject is defined on two levels. First, it is described as a core self emerging from the elementary subjective experience ${ }^{24}$. Secondly, the subject is defined as a more complex narrative or

23. I outlined a theory of media experience based on a match between semiotic tradition and current neuro-cognitive studies in Eugeni, 2010.

24. «[...] The (minimal or core) self possesses experiential reality, and is in fact identified with the first personal appearance of the experiential phenomena. At its most primitive, self-experience is simply a question of being pre-reflectively aware of one's own consciousness. [...] This is what makes experience subjective. Although there are different types of experiences (smelling hay, seeing a sunset, touching an ice cube, etc.), and although there are different types of experiential givenness (perceptual, imaginative, and recollective, etc.), there are common features as well. One such common feature is the quality of mineness. With the possible exception of certain pathological states [...], experiences that I live through in the first-person perspective are $m y$ experiences. [...] Phenomenal consciousness consequently entails a primitive form of self-referentiality or for-meness». Gallagher and Zahavi, 2008: 204; see in general 197-215. 
autobiographical self. However, this narrative self can not be thought of as radically different from the nuclear one; rather, the latter should be seen a development of the first, obtained through a continuous and coherent process of unfolding ${ }^{25}$. The critical issue here is that the element of continuity between the nuclear self and the narrative self is probably the subject's agency, that is the ability of the subjects to plan, act and monitor their movements and actions by means of an ongoing and unfolding activity of narrative account. Hence, the resulting idea of subject is that of a radically dynamical (id)entity, emerging from a continuous modulation of states of consciousness, and from a constantly repeated negotiation of the relationships between their own "sameness" and "selfhood"26.

25. «Conscious minds begin when self comes to mind, when brains add a self process to the mind mix, modestly at first but quite robustly later. The self is built in distinct steps grounded on the protoself. The first step is the generation of primordial feelings, the elementary feelings of existence that spring spontaneously from the protoself. Next is the core self. The core self is about action-specifically, about a relationship between the organism and the object. The core self unfolds in a sequence of images that describe an object engaging the protoself and modifying that protoself, including its primordial feelings. Finally, there is the autobiographical self. This self is defined in terms of biographical knowledge pertaining to the past as well as the anticipated future. The multiple images whose ensemble defines a biography generate pulses of core self whose aggregate constitutes an autobiographical self.» Damasio, 2010: 16-18. See also Damasio, 1999: 7 and 127.

26. «[...] on one side, identity as sameness (Latin idem, German Gleichbeit, French memete), on the other, identity as selfhood (Latin ipse, German Selbstheit, French ipseite). [...] It is with the question of permanence in time that the confrontation between our two versions of identity becomes a genuine problem for the first time. [...] When we speak of ourselves, we in fact have available to us two models of permanence in time which can be summed up in two expressions that are at once descriptive and emblematic: character and keeping one's word. In both of these, we easily recognize a permanence which we say belongs to us. My hypothesis is that the polarity of these two models of permanence with respect to persons results from the fact that the permanence of character expresses the almost complete mutual overlapping of the problematic of $i d e m$ and of ipse, while faithfulness to oneself in keeping one's word marks the extreme gap between the permanence of the self and that of the same and so attests fully to the irreducibility of the two problematics one to the other. [Moreover], the polarity I am going to examine suggests an intervention of narrative identity in the conceptual constitution of personal identity in the manner of a specific mediator between the pole of character, where idem and ipse tend to coincide, and the pole of self maintenance, where selfhood frees itself from sameness.» Ricoeur, 1992: 116 and 118-119. On the same topic (although with different ontological implications) see Daniel Dennett s idea of the narrative self as a «center of narrative gravity»: see for instance Dennett 1991: 412 - 430; A comparison between Dennett's and Ricoeur's theories on the narrative self is McCarthy, 2007. 


\section{References}

Aaron, M. (2007). Spectatorship. The Power of Looking On. London - New York: Wallflower Press.

Baudry, J.L. (1986). "Ideological effects of the Basic Cinematographic Apparatus" in ROSEN, P. (ed.). Narrative, Apparatus, Ideology. A Film Theory Reader. New York: Columbia U. P.: 286-298.

Branigan, E. (1984). Point of View in the Cinema. A Theory of Narration and Subjectivity in Classical Film, Berlin - New York: Mouton

CAsebier, A. (1991). Film and Phenomenology. Toward a Realistic Theory of Cinematic Representation. Cambridge - New York: Cambridge U.P., 1991

Casetti, F. (1991). Inside the Gaze. The Fiction Film and Its Spectator. Bloomington: Indiana University Press.

(1999), Theories of Cinema, 1945 to 1995. Revised and updated by the Author, Austin (TX): University of Texas Press.

Chateau, D. (ed.) (2011). Subjectivity. Filmic Representation and Spectator's Experience, Amsterdam: Amsterdam U.P.

Damasio, A. R. (2010). The Feeling of Wath Happens. Body and Emotion in the Making of Consciousness, New York, Harcourt Brace 1999.

(2010). Self Comes to Mind. Constructing the Conscious Brain. New York: Pantheon Books.

Dennett, D. C. (1991). Consciousness Explained. Boston (Mass.): Little Brown.

Doyle, P. A. (2003) Arresting images: crime and policing in front of the television camera, Toronto: University of Toronto Press.

Eugeni, R. (2010). Semiotica dei media. Le forme dell'esperienza, Roma: Carocci.

Ferrara, S. (2001). Steadicam. Techniques and Aesthetics. Oxford - Woburn (Mass.): Focal Press.

Gallagher, S., Zahavi, D. (2008). The phenomenological mind: an introduction to philosophy of mind and cognitive science. London - New York: Routledge.

Herlander, E. (2009). First Person Shooters. The Subjective Cyberspace. Covilha: University of Beira Interior Labcom.

Levin, T.Y. Frohne, U. Weibel, P. (2002). Ctrl [Space]. Rhetorics of Surveillance from Bentham to Big Brother, Karlsruhe - Cambridge and London: ZKM - MIT Press.

Mccarthy, J. (2007). Dennett and Ricoeur on the narrative self. Amherst (NY): Humanity Books.

Metz, C. (1982). "Story/Discourse (A Note on Two Kinds of Voyeurism)". In The Imaginary Signifier. Psychoanalysis and the Cinema. Bloomington: Indiana University Press: 91-98.

Petersen, J. K. (2001). Understanding surveillance technologies. Spy Devices, Their Origins and Applications. Boca Raton - London - New York - Washington: CRC Press. 
Rehac, B. (2008). "Genre profile: First-Person Shooting Games". In: WOLF M. J.P. (ed.). The Video Game Explosion. From PONG to Playstation and Beyond. Westport (Conn.) - London: Greenwod Press: 187-195.

Ricoeur, P. (1992). Oneself as another. Chicago - London: University of Chicago Press.

Shaw, S. (2008). Movies Consciousness. From Phenomenology to Deleuze. Jefferson (North Carolina) - London: McFarland.

Soвchack, V. (1992). The Address of the Eye. A Phenomenology of Film Experience, Princeton (NJ): Princeton U. P.

--2011). "The Man Who Wasn't There. Production of Subjectivity in Delmer Davies' Dark Passage”. In Chateau (ed.): 69-84.

Somaini, A. (2010). "Visual Surveillance. Transmedial Migrations of a Scopic Form". Acta Univ. Sapientiae, Film and Media Studies. n. 2: 145-159.

Wardrip-Fruin, N. Harrigan, P. (eds.) (2004). First Person. New Media as Story, Performance and Game, Cambridge (Mass.) - London: The MIT Press.

Ruggero Eugeni is Full Professor of Media Semiotics at the Catholic University of the Sacred Heart (Milan) and Director of Almed, the Postgraduate School in Media, Communication and Performing Arts of the same University.

Ruggero Eugeni's scientific interests are focused on the living / lived media experience, as defined both in historical / sociological terms, and in phenomenological / neurocognitive terms. His approach is mainly semiotic: he's currently working on the project of a «semiotic of media experience».

His leading works are Analisi semiotica dell'immagine. Pittura, illustrazione, fotografia, (Milano, new ed. 2004), Film, sapere, società. Per un'analisi sociosemiotica del testo cinematografico, (Milano, 1999), La relazione d'incanto. Studi su cinema e ipnosi (Milano, 2002). His most recent work is Semiotica dei media. Teoria e analisi dell'esperienza mediale (Media semiotics. Theory and analysis of media experience, 2010).

Several papers and preprints in English are available at the site Media / experience / semiotics (http://ruggeroeugeni.wordpress.com) and at Ruggero Eugeni’s university site (http://docenti.unicatt.it/eng/ruggero_eugeni) 